\section{latrogenic Displacement of an Impacted Mandibular Third Molar to the Neighbouring Pharyngeal Space}

Sir,

Extraction of difficult mandibular wisdom is accompanied with some reported unwanted complication sequelae resulted from the use of forcible inaccurate elevator manoeuvre that can lead to fracture of angle, ${ }^{1}$ periodontium laceration of neighbouring structures, inferior alveolar nerve injury, surgical emphysema, and haemorrhage. Difficult resistant tooth takes a long time for extraction and causes patient and surgeon fatigue. In these circumstances, the operator may be anxious and use excessive force against the surrounding living tissue, especially the bone. ${ }^{2,3}$

The current report describes an unusual case of iatrogenic displacement of impacted wisdom to the neighbouring lateral pharyngeal space during surgical extraction. Although this complication has been reported as a very rare accident in the literature; none of these iatrogenic errors had been unethically hidden from the patient or undiagnosed for two months. ${ }^{2,4}$

A 22-year female patient presented with an ulcerated wound in the right lateral pharyngeal region for 2 months. The patient thought that it is just an ulcer; however, it did not heal with any administered local or systemic medication.

Thorough patient history was taken in detail which included personal, dental and medical history which demonstrated no other medical abnormality. Complete intraoral and extraoral clinical examination was performed, which surprisingly revealed a history of surgical extraction 2 months back of the third molar \#48 on that side (Figure 1). Orthopantomogram (OPG) panoramic radiographic examination showed up impacted wisdom tooth which was horizontally posteriorly directed in the ascending ramus of the right side of the mandible. The patient was informed and the tooth was retrieved from the ulcerated area under local anaesthesia; and fortunately, the tooth was completely embedded in fibrotic soft tissue only. The wound healed in one weak without any other complaint(Figure 2).

Surgical exodontia is recommended to be performed by an oral surgeon specialist and not by a general practitioner. Specialisation in medical fields guarantees patient safety. ${ }^{5}$ The practitioner should use referral as a preventive way and in case of any iatrogenic medicinal errors, as the disappearance of the tooth in any adjacent fascial spaces, it is mandatory to inform the patient and refer the case to the maxillofacial surgeon without any delay, who is capable of using the best and highly specific advanced instruments and techniques. ${ }^{2}$

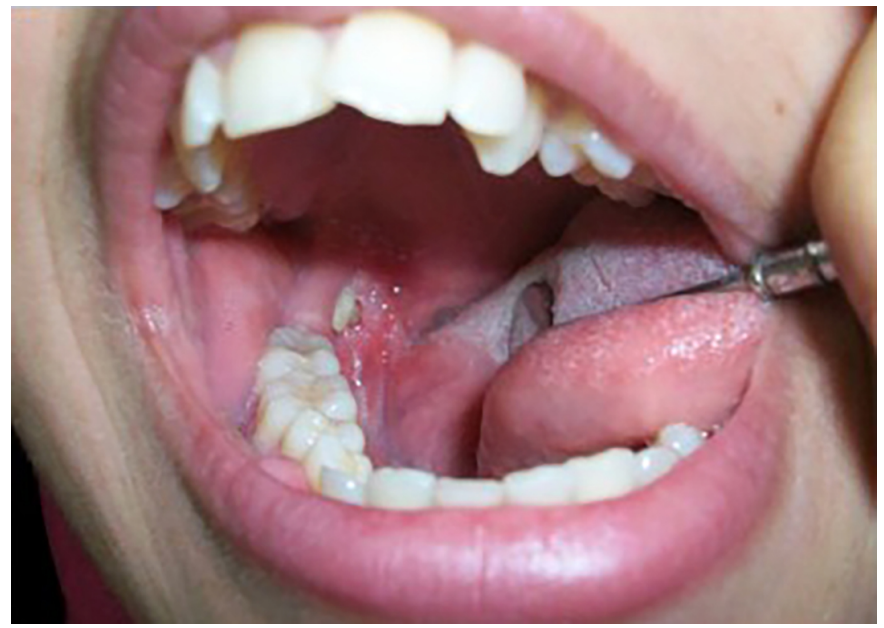

Figure 1: Intraoral examination showing tip of impacted third mandibular molartooth.

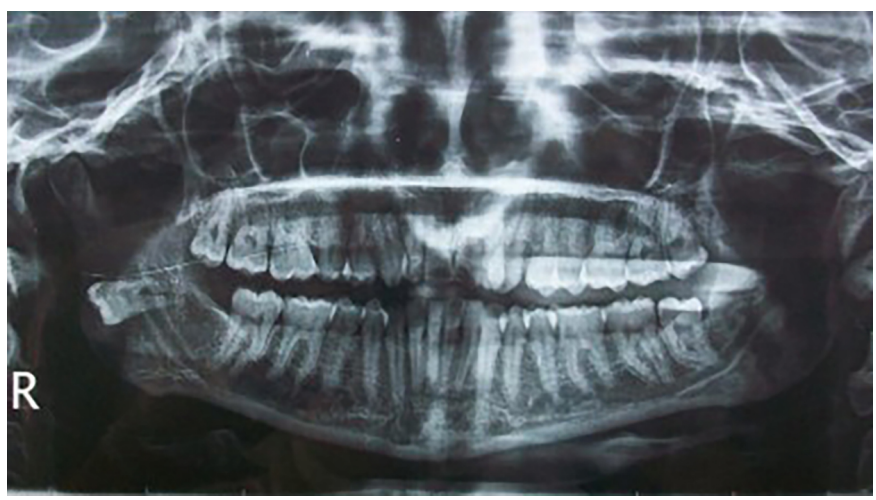

Figure 2: Orthopantomogram (OPG) panoramic radiographic view showing impacted wisdom tooth which is horizontally posteriorly directed in the ascending ramus of the right side of the mandible.

Additionally, the use of dental elevators should be very careful during complicated tooth surgical extraction, and training should be emphasised ${ }^{6}$. It must be used without any excessive force and the surgeon should respect the surrounding living tissues and bones. ${ }^{4}$ This current case report highlights the need to educate junior surgeons to take care during emergency accidents of wisdom surgery and alert them to follow ethical guidelines.

\section{CONFLICT OF INTEREST:}

Author declared no conflict of interest.

\section{AUTHOR'S CONTRIBUTION:}

SAE: Designed, edited the manuscript; reviewed and finally approved the manuscript.

\section{REFERENCES}

1. Samieirad S, Eshghpour M, Dashti R, Tohidi E, Javan AR, Mianbandi V. Correlation between lower third molar impaction types and mandibular angle and condylar fractures: A retrospective study. J Oral Maxillofac Surg 2019; 77(3):556-64. doi: 10.1016/j.joms.2018.09.028.

2. Medeiros N, Gaffrée G. Accidental displacement of inferior third molar into the lateral pharyngeal space: Case report. J Oral Maxillofac Surg 2008; 66(3):578-80. doi: 10.1016/ j.joms.2005.10.042. 
3. dos Santos Pereira R, da Silva JR, Bonardi JP, Hochuli-Vieira E. Lower third molar displaced to lateral pharyngeal space after mandibular angle fracture: A case report. Oral Maxillofac Surg 2018; 22(2):231-3. doi: 10.1007/ s10006-018-0673-2.

4. Yamashita Y, Iwai T, Oaki Y, Omura S, Aoki N, Tohnai I. Accidental displacement of mandibular third molar root into the sublingual space and delayed removal. Oral Surg 2018; 11(2):153-6. doi.org/10.1111/ors. 12303.

5. Huang IY, Chen CM, Chang SW, Yang CF, Chen $\mathrm{CH}$, Chen CM. Surgical management of accidentally displaced mandibular third molar into the pterygomandibular space: A case report. Kaohsiung J Med Sci 2007; 23(7):370-4. doi: 10.1016/S1607-551X(09)70424-3.

6. Bozkurt P, Erdem E. Management of upper and lower molars that are displaced into the neighbouring spaces. $\mathrm{Br} J$ Oral Maxillofac Surg 2017; 55(9):e49-e52. doi: 10.1016/ j.bjoms.2017.07.001.

Shadia A. Elsayed $d^{1,2}$

${ }^{1}$ Department of Oral and Maxillofacial Surgery, Faculty of Dental Medicine for Girls, Al Azhar University, Cairo, Egypt ${ }^{2}$ College of Dentistry, Taibah University, Almadinah Almunawwarrah, Saudi Arabia

Correspondence to: Dr. Shadia Abdelhameed Elsayed, Department of Oral and Maxillofacial Surgery, Faculty of Dental Medicine for Girls, Al-Azhar University, Cairo, Egypt E-mail: shadiaelsayed25@gmail.com

Received: September 17, 2019; Revised: November 13, 2019; Accepted: November 13, 2019

DOI: https://doi.org/10.29271/jcpsp.2020.10.1107 